Georgia State University

ScholarWorks @ Georgia State University

\title{
The Effect of Urinary Cadmium on Cardiovascular Fitness as Measured by VO2 Max in White, Black and Mexican Americans
}

Heartley Egwuogu

Follow this and additional works at: https://scholarworks.gsu.edu/iph_theses

Part of the Public Health Commons

\section{Recommended Citation}

Egwuogu, Heartley, "The Effect of Urinary Cadmium on Cardiovascular Fitness as Measured by VO2 Max in White, Black and Mexican Americans." Thesis, Georgia State University, 2007.

doi: https://doi.org/10.57709/1062244

This Thesis is brought to you for free and open access by the School of Public Health at ScholarWorks @ Georgia State University. It has been accepted for inclusion in Public Health Theses by an authorized administrator of ScholarWorks @ Georgia State University. For more information, please contact scholarworks@gsu.edu. 


\title{
Title Page
}

\begin{abstract}
TOPIC:
THE EFFECT OF URINARY CADMIUM ON CARDIOVASCULAR FITNESS AS MEASURED BY VO2 MAX IN WHITE, BLACK AND MEXICAN AMERICANS.
\end{abstract}

\author{
Heartley Egwuogu, RRT \\ B.Sc Georgia State University
}

\begin{abstract}
A Thesis Submitted to the Graduate Faculty Of Georgia State University in Partial Fulfillment of the

Requirements for the Degree
\end{abstract}

Masters of Public Health.

Atlanta, Georgia

2007

\section{Approval Page}


TOPIC:

THE EFFECT OF URINARY CADMIUM ON CARDIOVASCULAR FITNESS AS MEASURED BY VO2 MAX IN WHITE, BLACK AND MEXICAN AMERICANS

by

Heartley Egwuogu, RRT

B.Sc Georgia State University

Approved:

IKE S. OKOSUN, Ph.D, MS, MPH

Committee Chair

DEREK G. SHENDELL, D.ENV, MPH

Committee Member

LYNDA GOODFELLOW, ED.D, RRT, AE-C

Committee Member

$7 / 16 / 07$

Date 


\section{Author's Statement}

In presenting this thesis in partial fulfillment for the requirements for an advanced degree from Georgia State University, I agree that the library of the University shall make it available for inspection and circulation in accordance with its regulations governing materials of this type. I agree that permission to quote from, to copy from, or to publish this thesis may be granted by the author, or in her absence, by the professor under whose direction it was written, or in his absence, by the Associate Dean, College of Health and Human Sciences. Such quoting, copying, or publishing must be solely for scholarly purposes and will not involve potential financial gain. It is understood that any copying from or publication of this thesis which involves potential financial gain will not be allowed without written permission of the author.

Signature of Author 


\section{Notice to Borrowers}

All thesis deposited in Georgia State University Library must be used in accordance with the stipulations prescribed by the author in the preceding statement.

The Author of this thesis is: Heartley Egwuogu, RRT

Student's Name: Heartley Egwuogu, RRT

Street Address: 1870 Campbellton Rd

City, State, and Zip Code: Atlanta Georgia 30311

The Chair of the Committee for this thesis is:

Professor's Name: Ike S Okosun, Ph.D,MS,MPH

Department: Institute of Public Health

College: Health and Human Sciences

Georgia State University

P.O. Box 4018

Atlanta, Georgia 30302- 4018

Users of this thesis who are not regularly enrolled as students at Georgia State University are required to attest acceptance of the preceding stipulation by signing below. Libraries borrowing this thesis for the use of their patrons are required to see that each user records here the information requested.

\begin{tabular}{|l|l|l|l|}
\hline NAME OF USER & ADDRESS & DATE & $\begin{array}{c}\text { TYPE OF USE } \\
\text { (EXAMINATION ONLY } \\
\text { OR COPYING) }\end{array}$ \\
\hline & & & \\
\hline & & & \\
\hline & & & \\
\hline
\end{tabular}




\begin{abstract}
THE EFFECT OF URINARY CADMIUM ON CARDIOVASCULAR FITNESS AS MEASURED BY VO2 MAX IN WHITE, BLACK AND MEXICAN AMERICANS.
\end{abstract}

Heartley Egwuogu: Institute of Public Health Georgia State University Atlanta Georgia.

Context: Cadmium is an important predictor of lung function, including forced vital capacity, forced expiratory volume and peak flow. Current evidence supports the notion that cadmium may be an important risk factor for cardiovascular fitness.

Objectives: The purpose of this study was to determine the effect of cadmium exposure on cardiovascular fitness in representative sample of US white, blacks and Mexican Americans. The study also sought to determine if the relationship between cadmium and cardiovascular fitness varies by gender and racial/ethnic group.

Methods: The data utilized for this study were obtained from National Health and Nutrition Examination Survey (NHANES). One-thousand nine hundred and sixty three subjects with data on cardiovascular fitness were eligible for this investigation. In NHANES, cardiovascular measurements were taken in series consisting of two minutes warm up exercise, two-three minutes exercise testing and two minutes resting period .The goal was to elicit $75 \%$ of predetermined age-specific heart rate by the end of the stress test. Cadmium was measured in the laboratory by taking urine sample of participants. Gender and race/ethnic specific multivariate linear regression analyses were performed to determine relationship of urinary cadmium with $\mathrm{VO} 2$ max.

Results: There were gender and racial/ethnic difference in the relationship between urinary cadmium and VO2 max. In males and females, increased concentration of urinary cadmium was associated with decreased VO2 max across racial/ethnic groups (except in black males. The greatest negative association between cadmium and VO2 max was observed in black females (beta $=-0.330$ ) while the lowest value was recorded for white females (Beta $=-0.074)$. The association was statistically significant in white males (Beta=-0.402, $\mathrm{P}=0.020$ ) and Mexican American females (Beta=-0.290, $\mathrm{P}=0.026$ ).

Conclusion: There was inverse association between urinary cadmium and estimated VO2 max in a US nationally representative sample of White, Black and Mexican Americans. The impact of the gender and racial/ethnic differences in the association between urinary cadmium and VO2 max is not clear and warrants further investigation.

INDEX WORDS: Urinary Cadmium, Cardiovascular fitness, Estimated VO2max, Aerobic Potential 


\section{Acknowledgements}

My family members and friends who were supportive throughout the project.

The staff at the Institute of Public Health at Georgia State University Atlanta.

Staff and colleagues in the respiratory department of Grady Health Systems. 


\section{Table of Contents}

$\begin{array}{lr}\text { Abstract } & \text { i } \\ \text { Acknowledgements } & \text { ii } \\ \text { Table of Contents } & \text { iii } \\ \text { List of Figures and Tables } & \text { v }\end{array}$

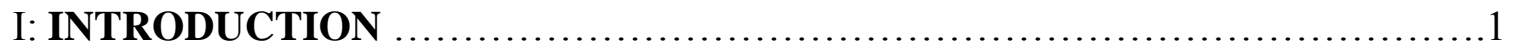

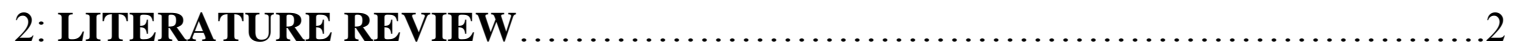

3: METHODOLOGY ..................................................

3.1 DATA SOURCE..........................................................

3.2 STUDY POPULATION...............................................

3.3 MEASUREMENTS..................................................... 10

3.4 COVARIATES............................................................. 11

3.5 ANALYSIS............................................................. 12

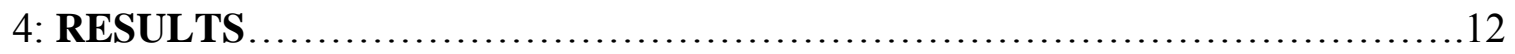

4.1 BASELINE CHARACTERISTICS.................................. 12 


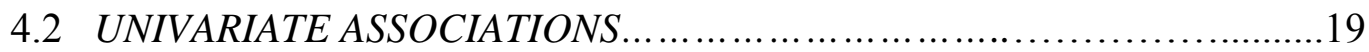

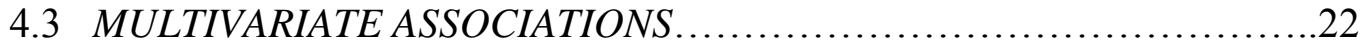

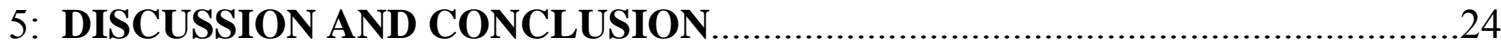

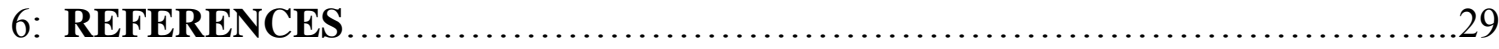

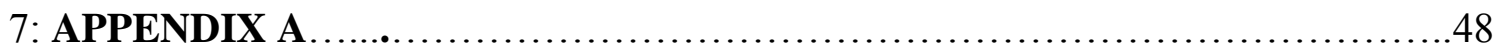

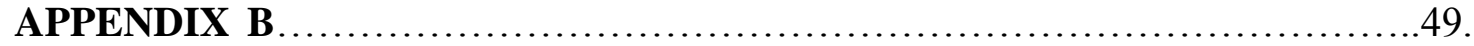




\section{List of Tables and Figures}

Table 1: Descriptive statistics of eligible male subjects............................14

Table 2: Descriptive statistics of eligible female subjects..........................15

Table 3: Univariate model of independent variables vs. VO2 max in eligible males.....21

Table 4: Univariate model of independent variables vs. VO2 max in eligible females..21

Table 5: Multivariate model of independent variables vs.VO2 max in eligible females--23

Figure 1: Normal distribution between urinary cadmium and estimated VO2 max.......16

Figure 2: Scatter plots of cadmium vs. VO2 max among males......................17

Figure 2: Scatter plots of cadmium vs. VO2 max among females.....................18 


\section{INTRODUCTION}

There is a large body of evidence linking environmental chemical pollutants to poor health in humans $[1,2,3]$. It is well recognized that environmental chemical pollutants play a crucial role in the respiratory status of those exposed to varying amounts of it [2, [4], particularly subjects who are immunocompromized. According to Agency for Toxic Substances and Disease Registry (ATSDR) of the Centers of Disease and Control and Prevention (CDC), there are over 250 chemical agents that pose threats to human health and the number of these chemicals is growing yearly with increasing research in chemical toxicology [5]. A majority of the new chemicals have not been adequately assessed for potential toxicity to humans. Sources of environmental chemical pollutants are numerous and include automobile exhaust, factory flares, burning of fossil fuel, refuse incineration, agriculture, tobacco smoke and industries that produce chemicals and pesticides. The most common groups of chemical pollutants released into the environment are chemical gases namely volatile organic compounds and heavy metals such as cadmium.

A variety of epidemiological data have suggested cadmium is an important predictor of lung function such as forced vital capacity, forced expiratory volume and peak flow $[6,7]$. Indeed, current evidence has suggested cadmium is a risk factor for cardiovascular fitness. However, little is known about the mechanism linking cadmium exposure to cardiovascular fitness. Miller et al (1974) reported elevated levels of cadmium resulted in lung injury characterized by acute inflammation, pulmonary fibrosis and emphysema 
[8]. Lung injury renders the alveolar membrane impervious to gaseous diffusion, resulting in impaired tissue oxygenation and lower $\mathrm{VO} 2$ max ultimately resulting in restrictive, obstructive and sometimes mixed restrictive and obstructive respiratory conditions in exposed subjects.

To further shed light on the effect of cadmium exposure on cardiovascular fitness, this study was designed to determine if the relationship between cadmium and cardiovascular fitness existed and perhaps may vary between gender and U.S racial groups. 


\section{LITERATURE REVIEW}

Cadmium is a heavy metal found in the earths crust. It does not occur alone by itself but in combination with other elements such as oxygen, chlorine and sulphur, forming complex metallic compounds. The chlorides and sulfides combinations are the most common cadmium complexes known. About 25,000-30,000 tons of cadmium are released into the air as fine suspended particulate matter each year [9]. The release of cadmium from human activities is estimated to be 4,000-14,000 tons per year from burning of fossil fuels, mining activities, coal-fired electric power plants, burning of household waste, hazardous waste sites and fertilizers applied to crops [9]. The most common sources of human exposure to cadmium is from cigarette smoke and foods. The average cadmium level in foods in the U.S has been estimated to be about 20-40 parts per million, lowest levels are found in fruits and beverages, but vegetable green leaves and potatoes are credited to have higher concentrations of cadmium [9].

\subsection{Exposure to Cadmium and Potential Adverse Health Effects.}

Several disorders have been associated with cadmium exposure. For example, intestinal ingestion of cadmium is associated with severe gastrointestinal epithelium irritation accompanied with nausea, pain, vomiting and diarrhea [10]. Several bone disorders have also been associated with high levels of cadmium including osteomalacia and osteoporosis [11]. 
Studies have demonstrated that breathing air with high cadmium concentrations can damage the lungs and cause death. Davidson et al (1988) reported that subjects who are exposed to cadmium showed abnormalities in lung function and radiological changes consistent with emphysema [12].

Other lung disorders and associated symptoms including asthma, pneumonia and wheezing have been associated with cadmium exposure. Children, elderly and subjects with respiratory problems are affected differently. Long-term exposure is known to be associated with persistent cough, impairment of respiratory functions, lung cancer and in severe cases death among these groups. The conditions may worsen during times of heavy pollution as in summer [13]. The common routes of exposure are by inhalation through nasal and oral passages. As the toxicants enter the body they accumulate in different tissues and organs and affect the human system producing harmful effects.

Cadmium inhalation over a long period of time even in low amounts has been associated with kidney damage [14]. Edling et al (1986), reported subjects exposed to $0.5 \mathrm{mg} \mathrm{Cd} / \mathrm{m}^{3}$ had induced renal damage in the form of beta 2-microglobunuria [15]. Iwata et al (1993) and Butchet et al (1990) also obtained similar results, these investigators found associations between levels of cadmium exposure with proteinuria and glomerular filtration rate among workers exposed to cadmium oxide in a nickel-cadmium battery manufacturing factory $[16,17]$. 


\section{$\underline{\text { 2.2 Cardiovascular Fitness per VO2 max }}$}

Cardiovascular fitness is characterized by efficient utilization of oxygen during aerobic condition in a living cell. It is quantified through measurement of volume of oxygen consumed at sub maximum activity (VO2 max). The unit of VO2 max is volume of oxygen consumed per kilogram of body weight per minute. Some studies have used body surface area in place of weight [18]. The advantage of using body surface area is to compare the effects of different body types and sizes on VO2 max. In an active person, as the intensity of exercise increases the amount of oxygen consumed increases, with further increases in exercise intensity the amount of oxygen available for cell oxidation no longer increases in the same proportion. The maximum amount of oxygen consumed at this point at maximum exercise is an indicator of cardiovascular fitness and aerobic potential.

Two theories may explain aerobic potential in living cells. The utilization theory suggests aerobic capacity is due to absence of oxidative enzymes within the walls of mitochondria of the cell. Mitochondria and oxidative enzymes determine the ability of the cell to utilize oxygen. Vigorous exercise can increase the amount of mitochondria and oxidative enzymes required for energy synthesis in the cells, resulting in increased VO2 max [19]. Many studies show a weak association between the amount of oxidative enzymes and VO2 max $[20,21]$. Presentation theory on the other hand, suggests that aerobic capacity is limited by the ability of the cardiovascular system to deliver oxygen to the living cells for energy synthesis. Improved blood circulation and tissue perfusion increase oxygen delivery resulting in higher VO2 max. Most studies are supportive of this theory. 
VO2 max depends on gender, age, lactic acid tolerance, environment, exposure to chemical pollutants, levels of physical activities, genetics and diet.

Men are twice as likely to utilize oxygen more than women. In a study, women were observed to have $20-25 \%$ lower VO2 max compared to men [20,22]. The differences were accounted for by the different amount of fat free mass, which in general are considerably higher in women than in men. Young adults across gender are more likely to utilize oxygen compared to older adults [19].

Athletes of the same body type may consume two to three times more oxygen than their non-athletic counterparts. Closely related to amount of oxygen consumed by athletes are lungs sizes. The larger the lungs, the greater the amounts of oxygen consumed. Generally, height is the most important factor that determines the size of the lungs, hence, taller athletes tends to have larger lung sizes and higher VO2 max compared to shorter athletes [23].Some people are genetically adapted to utilize oxygen more efficiently than others. This adaptation is linked to lactic acid metabolism. Lactic acid is released as a by product from anaerobic respiration and results in muscle fatigue during vigorous physical exercise. Studies have shown lactic acid production is associated with exhaustion during physical exercise [24].

VO2 max also depends on altitude. People living at higher attitudes have lower VO2 max compared to those living at lower altitudes. VO2 max declines at the rate of $1 \%$ per $100 \mathrm{~m}$ 
altitude gain above $1500 \mathrm{~m}$. The rationale behind it is people living at higher altitudes have decreased cardiac output characterized by low blood volume.

Heat stress has also been shown to affect VO2 max significantly. Gonzalez-Alonzo et al (2003), reported in trained humans, severe heat stress reduced VO2 max by accelerating the decline in cardiac output and mean arterial pressure which led to decrements in exercise time, muscle blood flow, Oxygen delivery and uptake [25].

Age is a significant factor affecting VO2 max. Many studies support findings that VO2 max decreases as age increases $[26,27]$. Age related decline in VO2 max is attributable to declines in maximal heart rate and cardiac output. Weiss et al (2006) reported VO2 max decreased with age more rapidly in elderly people older than sixty, the ageassociated decline was greater in men compared to women. Greater decline in Cardiac output in men compared to women accounted for the age-specific decline in VO2 max [28]. In spite of the age related decline in VO2 max, Bunyard et al (1998) reported age related decline in $\mathrm{VO} 2 \mathrm{max}$ can be attenuated by as much as $50 \%$ through regular physical and aerobic exercises [29].

\section{$\underline{\text { 2.3 Air Quality Issues Related to Cadmium and Cardiovascular Fitness }}$}

Ambient outdoor air is a mixture of complex particles and chemical pollutants with well known adverse effects on lung function and cardiovascular health. Many studies have been conducted on the effects of ambient air pollution exposure on the cardiovascular 
fitness among schoolchildren. One study found that children in higher population area had lower VO2 max than those in the lower pollution area [30]. The study also suggested if the students engaged in regular physical exercise in a polluted environment, it does not have any beneficial effect on cardiopulmonary fitness.

Indoor and outdoor training and physical exercise can significantly increase VO2 max. Periodic exercise three times a day for six months can increase VO2 max by $15-20 \%$ on average [31]. Sarsan et al (2005) found increases in VO2 max depended on the type of fitness exercise performed. Resistance training alone did not increase VO2 max, but combinations of resistance training with light aerobic exercise were found to result in improved exercise capacity and increased VO2 max [32].

The majority of studies on the effect of environmental pollutants on respiratory health have been focused on lung functions measurements such as forced vital capacity, forced expiratory volume, and peak flow rates. There are not enough studies however that use VO2 max for cardiovascular fitness as a measure of the predictive effect of chemical pollution among exposed subjects. 


\section{METHOD:}

\subsection{Data Source}

The population utilized for this study was obtained from the 1999-2000 National Health and Nutrition Examination Survey (NHANES) provided by CDC. No other year was considered in present study.

NHANES is a national data survey program whose basic goal is to monitor the health and nutritional status of adults and children in the United States (U.S) population. The program started in early1960's with the first three national examination surveys NHES, NHANES 1, and NHANES II conducted by the National Center for Health Statistics (NCHS) of the CDC. Prior to 1999, the survey was performed periodically but since then it has been done annually. Every year, the focus of the program changes to meet current needs. Participants are drawn throughout the country, from different states and counties. NHANES program combines physical examinations and laboratory tests with interviews based on validated surveys. The examination components include medical and dental examinations, physiological measurements and laboratory tests. The examinations are performed in specially designed mobile examination centers (MEC) by NHANES appointed physicians, medical and health technicians. The survey data collected during interviews include demographic, socioeconomic, and dietary and health related information.

The strength of NHANES program lies in its ability to monitor nutritional status, study potential associations of risk factors on some disease conditions, and monitoring of 
disease prevalence in the U.S population. A typical NHANES process starts by notification of local health and government officials in an upcoming survey. Then, individuals and households are randomly selected and notified through mail from the NCHS director. Institutional Review Board (IRB) approval and written informed consent is required for the use of human subjects. IRB consent was not obtained for earlier NHES, NHANES I and NHANES II. However, subsequent NHANES required IRB approval and written informed consent. Transportation to MEC lab is provided and at the end of the program participants are compensated. Medical findings are disclosed to participants and their health information is kept strictly confidential through the Health Insurance Portability and Accountability Act (HIPAA), which guards' protection of private medical information.

NHANES data is made available to users such as research organizations, universities, health care providers and educators on compact discs (CD) and diskettes. The data is also widely distributed on the World Wide Web. Others that rely on the data include U.S pubic health services agencies, the National Institute of Health, the Food and Drug Administration FDA, and CDC. NHANES also partners with other agencies such as the U.S Environmental Protection Agency (EPA) and Department of Agriculture to gather data related to environmental and agricultural pollution.

Past achievements of NHANES included creation of national growth charts. These charts are widely used by pediatricians worldwide to monitor growth rates in infants. Data from NHANES was instrumental in the development of policies necessary to achieve 
elimination of lead from gasoline and from solder in food and soft drink cans since 1970. NHANES provided the data that enabled better understanding of the emerging prevalence of overweight and obesity in the U.S. This awareness has lead to the creation of several programs aimed at monitoring diet and exercise within the population. Also, the prevalence of diabetes in the U.S was studied with NHANES, which prompted the federal government to create awareness of the condition, especially among minority population. More detailed information about NHANES can be found on the CDC web site [33].

\subsection{Study Population}

In NHANES, cardiovascular fitness test were administered to 9,965 participants who were between 12-49 years of age. Only subjects identified as White, Black and Mexican American were eligible for the study. Other racial/ethnic groups were not considered in the study due to small number. Two thousand five hundred and sixty one $(2,561)$ participants were excluded by NHANES based on medical conditions, physical limitations such as difficulty in walking, standing, having back or neck problems, fractures, eye problems, losing consciousness on a regular basis, having developmental problems or whose weight exceeded $350 \mathrm{lbs}$. Subjects with cardiovascular conditions excluded included those diagnosed with heart related problems, such as irregular heart rate, high blood pressure , hypertension, congestive heart failure, coronary artery diseases, angina, myocardial infarctions, stroke or having history of stroke. Also excluded were self reported heart problems or those with pacemaker and defibrillator, those taking blood or heart medications or those instructed to do only physical activity recommended by a 
doctor or not to participate in sports or any type of physical activity, those with chest pain, those with a resting heart rate greater than 100 beats per minute and hypertensive individuals. Also subjects with lung and breathing conditions such as those having shortness of breath on exertions, orthopnea, asthma, sleep apnea, chronic obstructive pulmonary disease (COPD), or self reported lung and breathing problems were ineligible in this study. The screening was done prior to a tread mill testing.

Other medical conditions used to disqualify subjects for the study included respiratory problems such as persistent coughing; obstructive sleep apnea, those using breathing medications or whose doctor has told them they have problems related to sitting, those taking medication for wheezes or whose doctor prescribed wheezing medication, those with limited activity due to wheezing, awakened by trouble breathing, those who stop for breath after walking one hundred yards at one 's own pace and missing values for VO2 max. Also, excluded are those pregnant, and those exposed to other chemical pollutants such as volatile organic compounds and those having significant concentrations of heavy metals in their urine sample. In the end 1963 subjects were eligible for the present study's analysis.

\subsection{Measurements}

Cardiovascular fitness is often measured in the laboratory by conducting exercise stress tests on a treadmill or cycle ergometer. During the process, the amounts of oxygen utilized and carbon dioxide expired are measured at predetermined sub maximal exercise capacity to determine the VO2 max. In NHANES, cardiovascular fitness was performed 
by trained technicians. Measures of heart rate, respiratory rate and blood pressure were used as surrogate measures for VO2 max. These measurements were taken in series consisting of about two minute warm up exercise, three minute exercise testing performed twice and a two minute resting period .The goal was to elicit $75 \%$ of a predetermined age-specific heart rate by the end of the stress test. The heart rate was continuously measured at each stage and the blood pressure was measured at the end of each stage of the exercise. VO2 max was estimated by substituting these measures into a derived equation shown in Appendix A.

. Cadmium was measured in the laboratory by taking urine samples of participants and then passing them through the process of Inductively Coupled Plasma Mass Spectrometry (ICP-MS). Because molybdenum tends to interfere with cadmium measurements leading to inaccurate results, cadmium values were corrected using the Dynamic Reaction Cell (DRC) Technology to eliminate the effect of molybdenum oxide in the sample. Urine samples were analyzed by NHANES appointed and certified laboratory technicians [33].

\subsection{Covariates}

In NHANES, age, gender and ethnicity were determined using self-reported questionnaires. Standing height and body weight were determined by laboratory measurements in centimeter $\mathrm{cm}$ and kilogram $\mathrm{Kg}$ respectively. Average level of physical activity was self reported and categorized into two groups. The first group was composed of those who do not Walk- about very much during the day and those who walk-about a lot during the day but do not lift or carry things often . The second group 
was composed of those who either lift light loads, climb stairs or hills and perform heavy work or carry heavy loads. Muscle strengthening activities were self reported and were categorized into two groups. The first group was composed of those who perform any physical activities specifically designed to strengthen the muscles such as lifting of weights, push ups, sit ups, or any other such activities. The second group was composed of those who do not perform any muscle enhancing activities. Body mass index (BMI) was calculated by dividing the weight in $\mathrm{Kg}$ by the square of the height in $\mathrm{cm}$. Systolic and diastolic blood pressures were determined using sphygmomanometer. Income was self reported and consisted of subjects within four income groups; $\$ 0-24,999, \$ 25,000$ $\$ 54,000, \$ 55,000-\$ 74,999$ and above $\$ 75,000$. Education was also self reported and consisted of subjects within three groups; less than high school, high school and greater than high school.

\section{$\underline{3.5}$ Analysis.}

The characteristics of each group of the population were evaluated and the differences between groups were evaluated using one-way analysis of variance (ANOVA) for continuous variables and chi square analysis for categorical variables. An approximate normal distribution curve of cadmium in relation to gender and ethnic group was performed to determine the distribution of cadmium within the population. Scatter plots of urinary cadmium against estimated VO2 max stratified by gender and by race/ethnicity was performed to gain insight into the relationship between the two variables. Gender and ethnic specific relationship of cadmium with VO2 max was evaluated by univariate regression analysis. The potential relationships of other independent variables with VO2 
max was also evaluated by univariate regression analysis. Separate multivariate linear regression analyses were performed to test gender and racial/ethnic-specific relationships of cadmium with VO2 max controlling for age, average level of physical activities, muscle strengthening exercises activities, weight, standing height, and BMI. Statistical significance was determined using $\mathrm{p}<0.05$. Data management and analysis was performed using Statistical Package Software (SPSS) version 15.0. 


\subsection{RESULTS}

\subsection{Baseline Characteristics}

The basic characteristics of eligible male and female subjects, stratified by race/ethnicity for this study are shown in Table 1 and Table 2, respectively. Analyses of gender specific differences for continuous variable were done using one-way ANOVA. Gender specific differences among white, black and Mexican-Americans for categorical variables were analyzed using Chi Square. As shown in Table 1, among males there were statistically significant differences in predicted VO2 max, age at screening, weight, standing height, diastolic blood pressure, education, annual household income and muscle strengthening activity across racial/ethnic groups $(\mathrm{P}<.001)$. Among females as shown in Table 2 , there were statistically significant differences in estimated VO2 max, age at screening, weight, standing height, body mass index, diastolic blood pressure (DBP) education and annual household income among white, black and Mexican American females $(\mathrm{P}<.001)$.

Among males, black male had the highest mean for predicted and estimated VO2 max, max. Also differences between the racial/ethnic group was statistically significant with respect to predicted VO2max $(\mathrm{P}=0.002)$. Among females, Mexican American females had the highest mean for predicted and estimated VO2. Also differences between the 
racial/ethnic group was statistically significant with respect to estimated VO2max $(\mathrm{P}<0.001)$

Among males, black male had the highest mean for urinary cadmium. However, racial/ethnic difference was not statistically significant. Also among females, black female had the highest mean for urinary cadmium. But racial/ethnic difference was marginally significant $(\mathrm{P}=0.091)$. 
Table 1: Descriptive Statistics of Eligible Male Subjects, NHANES 1999-2000

\begin{tabular}{|c|c|c|c|c|c|c|c|}
\hline & \multicolumn{2}{|c|}{ White Male } & \multicolumn{2}{|c|}{ Black Male } & \multicolumn{2}{|c|}{ Mex. Am Male } & \multirow[b]{2}{*}{ P-Val } \\
\hline & Mean & S.D & Mean & S.D & Mean & S.D & \\
\hline Predicted VO2 Max (ml/kg/min) & 47.86 & 8.91 & 49.71 & 8.25 & 47.52 & 7.85 & $0.002^{*}$ \\
\hline Estimated VO2Max ( $\mathrm{ml} / \mathrm{kg} / \mathrm{min})$ & 46.22 & 9.16 & 47.29 & 11.31 & 46.69 & 11.31 & 0.507 \\
\hline Age at Screening & 23.11 & 10.68 & 18.70 & 7.45 & 18.96 & 8.32 & $<.001^{*}$ \\
\hline Weight $(\mathrm{kg})$ & 75.71 & 21.37 & 72.50 & 21.55 & 70.66 & 19.84 & $0.006^{*}$ \\
\hline Standing Height $(\mathrm{cm})$ & 175.1 & 10.16 & 173.1 & 10.13 & 167.9 & 8.84 & $<.001^{*}$ \\
\hline Body Mass Index $(\mathrm{kg} / \mathrm{m} * * 2)$ & 24.36 & 5.38 & 23.89 & 5.94 & 24.78 & 5.77 & 0.130 \\
\hline SBP Average Reported & 114.1 & 11.35 & 115.6 & 11.88 & 114.1 & 10.89 & 0.151 \\
\hline DBP Average Reported & 67.34 & 13.23 & 63.80 & 14,97 & 63.89 & 13.42 & $0.002^{*}$ \\
\hline \multirow[t]{2}{*}{ Cadmium, Urine (ng/mL) } & 0.191 & 0.164 & 0.262 & 0.211 & 0.221 & 0.218 & 0.96 \\
\hline & Freq & $\%$ & Freq & $\%$ & Freq & $\%$ & $\chi^{2}$ \\
\hline Education: & & & & & & & $<.001^{*}$ \\
\hline Less than high school & 142 & 50.4 & 207 & 77.5 & 365 & 81.7 & \\
\hline High School & 38 & 13.5 & 25 & 9.4 & 43 & 9.6 & \\
\hline Greater than high School & 102 & 36.2 & 35 & 13.1 & 39 & 8.7 & \\
\hline Annual Household Income & & & & & & & $<.001^{*}$ \\
\hline$\$ 0-24999$ & 42 & 14.5 & 95 & 35.6 & 168 & 37.6 & \\
\hline$\$ 25000-54999$ & 76 & 27.0 & 67 & 25.1 & 117 & 26.2 & \\
\hline$\$ 55000-74999$ & 43 & 15.2 & 30 & 11.2 & 39 & 8.7 & \\
\hline Above $\$ 75000$ & 90 & 31.9 & 29 & 10.9 & 33 & 7.4 & \\
\hline Average Level of Physical Act. & & & & & & & 0.102 \\
\hline Light & 127 & 45 & 118 & 44.2 & 179 & 40 & \\
\hline Heavy & 74 & 26.2 & 43 & 16.1 & 96 & 21.5 & \\
\hline Muscle Strengthening Act & & & & & & & $0.015^{*}$ \\
\hline Light & 185 & 65.6 & 181 & 67.8 & 261 & 58.4 & \\
\hline Heavy & 93 & 33.0 & 80 & 30.0 & 180 & 40.3 & \\
\hline Industry Group & & & & & & & 0.375 \\
\hline Agricultural/Mining & 6 & 2.1 & 4 & 1.5 & 14 & 3.1 & \\
\hline Construction & 7 & 2.5 & 8 & 3.0 & 21 & 4.7 & \\
\hline Manufacturing & 17 & 6.0 & 22 & 8.2 & 26 & 5.8 & \\
\hline Serving & 85 & 30.1 & 81 & 30.3 & 127 & 42.1 & \\
\hline
\end{tabular}

* Statistically significant at $95 \%$ confidence interval. 
Table 2: Descriptive Statistics of Eligible Female Subjects, NHANES 1999-2000

\begin{tabular}{|c|c|c|c|c|c|c|c|}
\hline & \multicolumn{2}{|c|}{ White female } & \multicolumn{2}{|c|}{ Black female } & \multicolumn{2}{|c|}{$\begin{array}{l}\text { Me Am. } \\
\text { Female }\end{array}$} & \multirow[b]{2}{*}{ P-Val } \\
\hline & Mean & S.D & Mean & S.D & Mean & S.D & \\
\hline Predicted VO2 Max (ml/kg/min) & 33.83 & 8.59 & 33.18 & 8.81 & 34.41 & 7.45 & 0.152 \\
\hline Estimated VO2Max ( $\mathrm{ml} / \mathrm{kg} / \mathrm{min})$ & 37.42 & 7.80 & 36.80 & 8.89 & 40.24 & 10.40 & $<.001^{*}$ \\
\hline Age at Screening & 25.00 & 11.55 & 19.98 & 9.56 & 19.60 & 8.82 & $<.001^{*}<-20$ \\
\hline Weight $(\mathrm{kg})$ & 65.82 & 18.05 & 71.30 & 21.02 & 63.51 & 15.47 & $<.001^{*}<-20$ \\
\hline Standing Height $(\mathrm{cm})$ & 163.9 & 6.59 & 163.1 & 6.23 & 158.1 & 6.28 & $<.001^{*}$ \\
\hline Body Mass Index $(\mathrm{kg} / \mathrm{m} * * 2)$ & 24.48 & 6.08 & 26.69 & 7.50 & 25.34 & 5.72 & 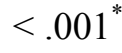 \\
\hline SBP Average Reported & 108.9 & 10.65 & 109.6 & 9.80 & 109.3 & 10.24 & 0.682 \\
\hline DBP Average Reported & 67.80 & 10.47 & 65.73 & 11.39 & 65.90 & 9.99 & $0.034^{*}$ \\
\hline \multirow[t]{2}{*}{ Cadmium, Urine $(\mathrm{ng} / \mathrm{mL})$} & 0.204 & 0.166 & 0.296 & 0.281 & 0.252 & 0.283 & 0.091 \\
\hline & Freq & $\%$ & Freq & $\%$ & Freq & $\%$ & $\chi^{2}$ \\
\hline Education: & & & & & & & $<.001^{*}$ \\
\hline Less than high school & 123 & 45.7 & 191 & 72.1 & 326 & 75.3 & \\
\hline High School & 29 & 10.8 & 26 & 9.8 & 58 & 13.4 & \\
\hline Greater than high School & 116 & 43.1 & 48 & 18.1 & 49 & 11.3 & \\
\hline Annual Household Income & & & & & & & $<.001^{*}$ \\
\hline \$0-24999 & 46 & 17.1 & 97 & 36.6 & 159 & 36.7 & \\
\hline$\$ 25000-54999$ & 59 & 21.9 & 66 & 24.9 & 123 & 28.4 & \\
\hline$\$ 55000-74999$ & 38 & 14.1 & 28 & 10.6 & 35 & 8.1 & \\
\hline Above $\$ 75000$ & 88 & 32.7 & 33 & 12.5 & 29 & 6.7 & \\
\hline Average Level of Physical Act. & & & & & & & 0.103 \\
\hline Light & 162 & 60.2 & 125 & 47.2 & 202 & 46.7 & \\
\hline Heavy & 31 & 11.5 & 21 & 7.9 & 57 & 13.2 & \\
\hline Muscle Strengthening Act & & & & & & & 0.660 \\
\hline Light & 121 & 45.0 & 112 & 42.3 & 197 & 45.5 & \\
\hline Heavy & 147 & 54.6 & 153 & 57.7 & 234 & 54.0 & \\
\hline Industry Group & & & & & & & 0.767 \\
\hline Agricultural/Mining & 3 & 1.1 & 5 & 1.9 & 6 & 1.4 & \\
\hline Construction & 10 & 3.7 & 13 & 4.9 & 13 & 3.0 & \\
\hline Manufacturing & 13 & 4.8 & 22 & 6.4 & 25 & 5.8 & \\
\hline Servicing & 85 & 31.6 & 80 & 30.2 & 193 & 44.6 & \\
\hline
\end{tabular}

* Statistically significant at $95 \%$ confidence interval. 
The distribution of cadmium (a) and estimated VO2 max (b) in the studied population is shown in Figure 1. As shown, the distribution of Cadmium and estimated VO2 max tended to approximate normal distribution. Cadmium was skewed to the left.
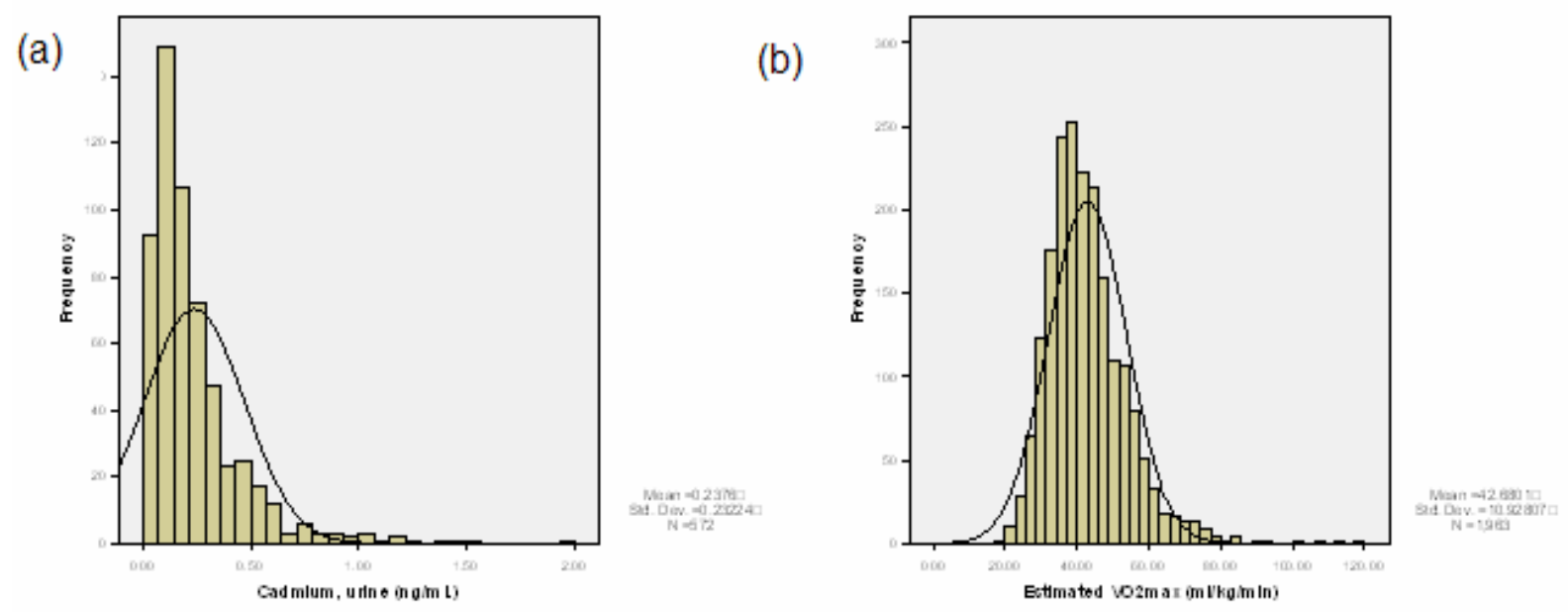

Figure 1: Normal Distribution of Cadmium and Estimated VO2 max. NHANES 1999-2000

We performed scatter plots between estimated cadmium and VO2 max to determine the nature of the relationship between the two variables by race/ethnicity in males and females as shown in Figure 2 and Figure 3, respectively. As shown, the plots illustrated low negative correlations between estimated VO2 max and levels of cadmium overall per $\mathrm{R}^{2}$ values. In males, cadmium was inversely related to estimated VO2 max among Whites $(\mathrm{r}=-0.065)$ and Mexican Americans $(\mathrm{r}=-0.004)$, among Blacks however, the relationship was positive $(\mathrm{r}=0.002)$. A similar negative correlation between cadmium and VO2 max was also evident in White $(\mathrm{r}=-0.019)$, Black $(\mathrm{r}=-0.073)$ and Mexican American $(\mathrm{r}=-0.028)$ females. 


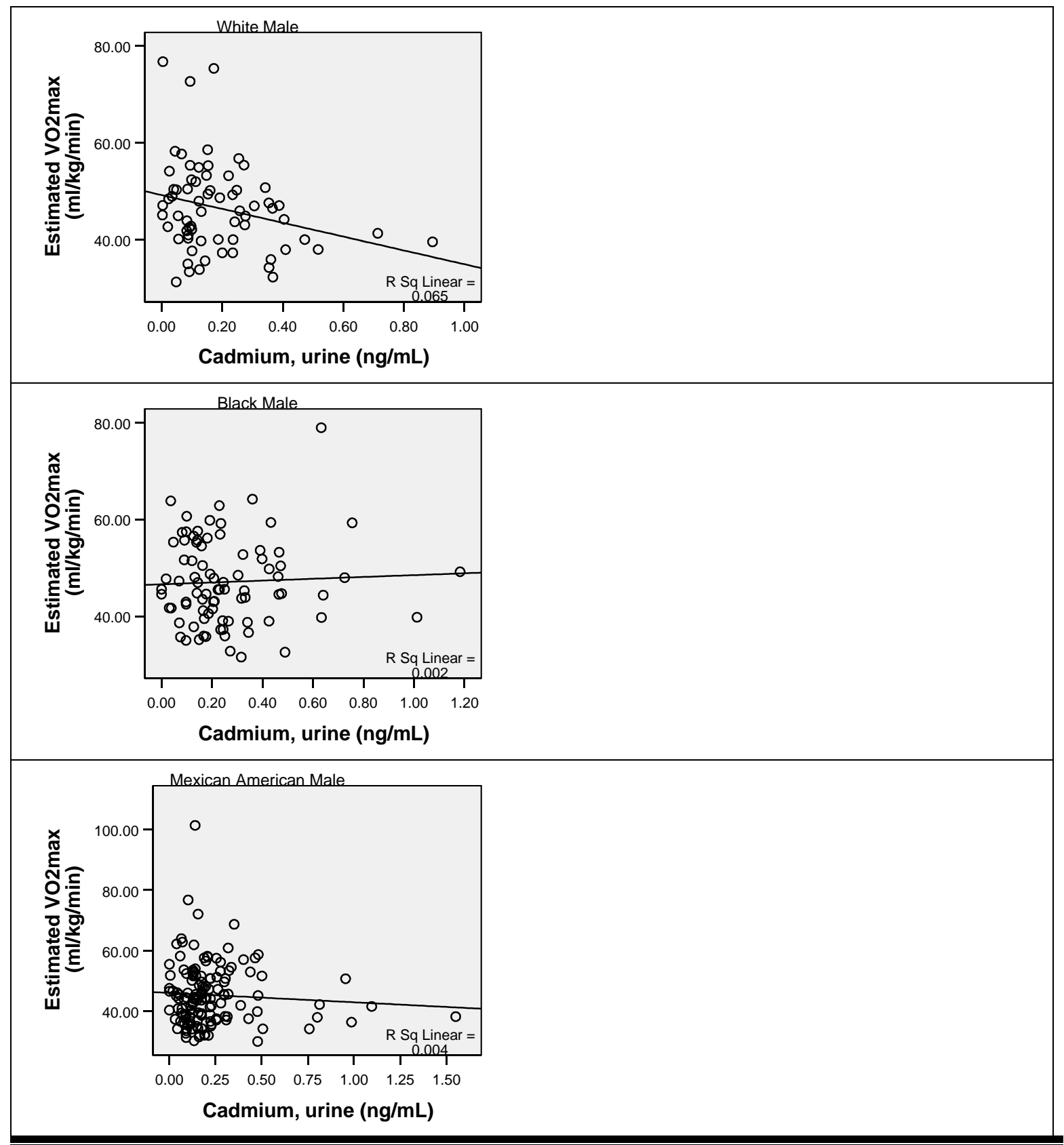

FIGURE 2: Scatter Plot of Cadmium Versus VO2 max Among Males by Race/Ethnicit,. NHANES 1999-2000. 


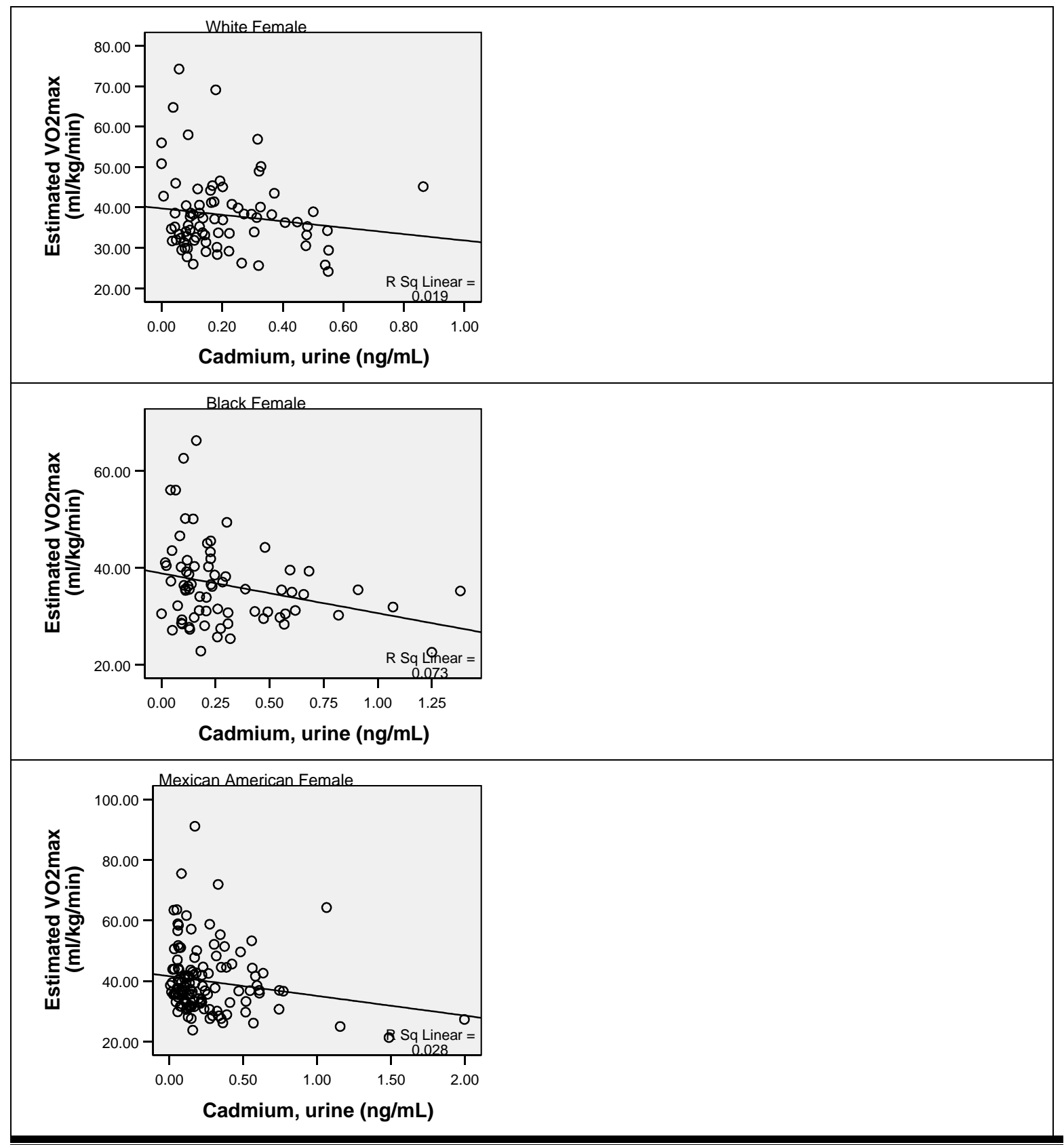

FIGURE 3: Scatter Plot of Cadmium Versus .VO2 max Among Eligible Females by Race/Ethnicity, NHANES 1999-2000. 


\subsection{Univariate association between selected independent factors and estimated VO2 max.}

Results of univariate analysis of the association between selected independent variables and estimated VO2 max among males and female subjects stratified by race/ethnicity are shown in Table 3 and Table 4, respectively.

Among white males sampled, cadmium, body mass index, systolic blood pressure (SBP), diastolic blood pressure (DBP), education, annual household and industrial group were negatively associated with estimated VO2 max. The association was statistically significant with respect to cadmium(Beta $=-0.255, \mathrm{p}=0.034)$ and marginally significant for weight $($ Beta $=-0.115, \mathrm{p}=0.054)$ and education $(\mathrm{Beta}=-0.109, \mathrm{p}=0.067)$.Although standing height, average level of physical activity and muscle strengthening activity were positively associated with estimated VO2 max, the association was not statistically significant. On the other hand, among white females, the independent variables were negatively associated with estimated VO2 max, except with annual household income. The association was statistically significant with respect to age $($ Beta $=-0.200, p=0.001)$, weight $($ Beta $=-0.263, p=<0.001)$, body mass index $($ Beta $=-0.257, p=<0.001)$, DBP $(B e t a=-0.211, p=0.026)$, education $(B e t a=-0.211, p=0.010)$ and muscle strengthening activity $($ Beta $=-0.161, \mathrm{p}=0.008)$.

Among sampled black males, cadmium was positively associated with estimated VO2 $\max$, but the association was not statistically significant (Beta $=0.045, \mathrm{P}=0.681$ ). However, age, weight, standing height, body mass index, SBP, DBP, education, annual household 
income, average level of physical activity, muscle strengthening activity and industrial group were negatively associated with estimated VO2 max. The association was statistically significant with respect to age $($ Beta $=-0.181, \mathrm{p}=0.003)$, weight $\left(\mathrm{Beta}^{=-0.339}\right.$, $\mathrm{P}=<0.001)$, body mass index $($ Beta $=-0.373, \mathrm{p}=<0.001)$ and systolic blood pressure $(B e t a=-0.138, p=0.0025$. Associations were marginally significant with respect to education $(\mathrm{Beta}=-0.117, \mathrm{P}=0.057)$ and annual household income $($ Beta $=-0.118, \mathrm{p}=0.080)$. Similarly, among black females the variables were negatively associated with estimated VO2 max except for average level of physical activity and industrial group/current job. The association was statistically significant with respect to cadmium (Beta=-0.270, $\mathrm{p}=0.021)$, age $($ Beta $=-0.285, \mathrm{p}=<0.001)$, weight $($ Beta $=-0.286, \mathrm{p}=<0.001)$, body mass index $($ Beta $=-0.283, p=<0.001)$, SBP $($ Beta $=-0.154, p=0.012)$, education $($ Beta $=-0.247$, $\mathrm{p}=<0.001)$ and industrial group $(\mathrm{Beta}=0.204, \mathrm{P}=0.029)$, but only marginally significant for $\operatorname{DBP}(\operatorname{Beta}=-0.107, \mathrm{p}=0.082)$.

Among sampled Mexican American males, the independent factors were negatively associated with estimated VO2 max except for standing height, DBP and average level of physical activity. The association was statistically significant with respect to weight $($ Beta $=-0.228, \mathrm{p}=<0.001)$, body mass index $($ Beta $=-0.268, \mathrm{P}=<0.001), \mathrm{SBP}\left(\mathrm{Beta}^{=}=-0.154\right.$, $\mathrm{P}=0.001)$ and education $(\mathrm{Beta}=-0.144, \mathrm{P}=0.002$ ). The association was marginally significant with respect to age $(\mathrm{Beta}=-0.082, \mathrm{p}=0.085)$, average level of physical activity $(B e t a=0.110, p=0.069)$ and muscle strengthening activity $($ Beta $=-0.080, p=0.092)$. Among Mexican American females, the independent factors were negatively associated with estimated VO2 max except for annual household income and muscle strengthening 


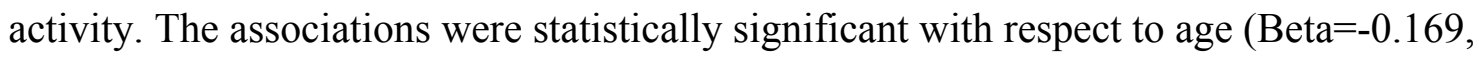
$\mathrm{P}=0.008)$, weight (Beta $=-0.104, \mathrm{P}=0.030)$ standing height $($ Beta $=-0.107, \mathrm{P}=0.026)$ and education $(B e t a=-0.104, P=0.030)$, but only marginally significant for cadmium with VO2max $($ Beta $=-0.169, \mathrm{P}=0.058)$. 
Table 3: Univariate Model of Independent Variable Vs. VO2 max in Eligible

Male Subjects. NHANES 1999-2000

\begin{tabular}{|c|c|c|c|c|c|c|}
\hline & \multicolumn{2}{|c|}{ White Male } & \multicolumn{2}{|c|}{ Black Male } & \multicolumn{2}{|c|}{$\begin{array}{l}\text { Mex.Ame. } \\
\text { Male }\end{array}$} \\
\hline & Beta & P-Val & Beta & P-Val & Beta & P-Val \\
\hline Cadmium & -0.255 & $0.034^{*}$ & 0.045 & 0.681 & -0.066 & 0.437 \\
\hline Age & -0.088 & 0.139 & -0.281 & $0.003^{*}$ & -0.082 & 0.085 \\
\hline Weight & -0.115 & 0.054 & -0.339 & $0.000^{*}$ & -0.228 & $0.000^{*}$ \\
\hline Standing Height (cm) & 0.025 & 0.682 & -0.098 & 0.111 & 0.019 & 0.688 \\
\hline Body Mass Index & -0.160 & $0.007^{*}$ & -0.373 & $0.000^{*}$ & -0.268 & $0.000^{*}$ \\
\hline SBP & -0.083 & 0.162 & -0.138 & $0.025^{*}$ & -0.154 & $0.001^{*}$ \\
\hline DBP & -0.095 & 0.113 & -0.096 & 0.119 & 0.004 & 0.934 \\
\hline Education & -0.109 & 0.067 & -0.117 & 0.057 & -0.144 & $0.002^{*}$ \\
\hline Annual Household Income & -0.008 & 0.897 & -0.118 & 0.080 & -0.051 & 0.334 \\
\hline Avg. Level of Physical Activity & 0.081 & 0.255 & -0.105 & 0.185 & 0.110 & 0.069 \\
\hline Muscle Strengthening Activities & 0.002 & 0.974 & -0.073 & 0.242 & -0.080 & 0.092 \\
\hline Industrial Group: Current Job & -0.079 & 0.401 & -0.004 & 0.966 & -0.028 & 0.701 \\
\hline
\end{tabular}

Table 4:Univariate Model of Independent Variable Versus. VO2 max in Eligible

Female Subject. NHANES 1999-2000

\begin{tabular}{|c|c|c|c|c|c|c|}
\hline & \multicolumn{2}{|c|}{ White Female } & \multicolumn{2}{|c|}{ Black Female } & \multicolumn{2}{|c|}{$\begin{array}{l}\text { Mex.Ame. } \\
\text { Female }\end{array}$} \\
\hline & Beta & P-Val & Beta & P-Val & Beta & P-Val \\
\hline Cadmium & -0.139 & 0.226 & -0.270 & $0.021^{*}$ & -0.169 & 0.058 \\
\hline Age & -0.200 & $0.010^{*}$ & -0.285 & $0.000^{*}$ & -0.127 & $0.008^{*}$ \\
\hline Weight & -0.263 & $0.000^{*}$ & -0.286 & $0.000^{*}$ & -0.104 & $0.030^{*}$ \\
\hline Standing Height $(\mathrm{cm})$ & -0.084 & 0.171 & -0.099 & 0.110 & -0.107 & $0.026^{*}$ \\
\hline Body Mass Index & -0.257 & $0.000^{*}$ & -0.283 & $0.000^{*}$ & -0.077 & 0.112 \\
\hline SBP & -0.098 & 0.110 & -0.154 & $0.012^{*}$ & -0.049 & 0.312 \\
\hline DBP & -0.135 & $0.026^{*}$ & -0.107 & 0.082 & -0.055 & 0.256 \\
\hline Education & -0.211 & $0.001^{*}$ & -0.247 & $0.000^{*}$ & -0.104 & $0.030^{*}$ \\
\hline Annual Household Income & 0.044 & 0.503 & -0.086 & 0.198 & 0.014 & 0.797 \\
\hline Avg. Level of Physical Activity & -0.002 & 0.983 & 0.095 & 0.252 & -0.022 & 0.720 \\
\hline Muscle Strengthening Activities & -0.161 & $0.008^{*}$ & -0.093 & 0.131 & 0.036 & 0.459 \\
\hline Industrial Group: Current Job & -0.071 & 0.464 & 0.204 & $0.029^{*}$ & -0.028 & 0.701 \\
\hline
\end{tabular}

* Statistically significant at $95 \%$ confidence interval. 


\subsection{Multivariate association between selected independent factors and VO2 max}

Results of the relationship between cadmium and estimated VO2 max controlling for age, standing height, average level of physical activity each day, muscle strengthening activity, weight and body mass index stratified by gender and race/ethnicity are shown in Table 5 . As shown in table 5, cadmium was negatively associated with estimated VO2 max in both males and female across races/ethnicity except in black males. Among the negatively associated groups, black females had the highest degree of association (beta=$0.330)$ and the lowest was recorded for white females (Beta $=-0.074)$.

Finally the association between cadmium and VO2 max was statistically significant among white males $($ Beta $=-0.402, \mathrm{P}$-value $=0.020)$ and Mexican American females (Beta $=-0.290, \mathrm{P}$-value $=0.026$ ). Variables controlled in the multivariate regression model were selected based on known association with $\mathrm{VO} 2$ max, supported by literature review. 
Table5: Multivariate model of Cadmium Versus VO2 max in Male \& Female

Subjects Controlling for Confounding Variables, NHANES 1999-2000

\begin{tabular}{l|cc|cc|cc|}
\hline \hline & \multicolumn{2}{|c|}{ White } & \multicolumn{2}{c|}{ Black } & \multicolumn{2}{c|}{ Mex.American } \\
\hline MALE & Beta & P-Val & Beta & P-Val & Beta & p-Val \\
\hline Cadmium & -0.402 & $0.020^{*}$ & 0.187 & 0.185 & -0.079 & 0.487 \\
Age & 0.338 & 0.059 & -0.315 & 0.035 & -0.100 & 0.400 \\
Weight & 2.939 & 0.138 & 2.064 & 0.205 & -1.695 & 0.180 \\
Standing Height (cm) & -1.158 & 0.418 & -0.862 & 0.182 & 0.699 & 0.104 \\
Body Mass Index & -2.676 & 0.100 & -2.124 & 0.145 & 1.182 & 0.304 \\
Avg. Level of Physical Act & 0.306 & 0.039 & -0.055 & 0.708 & 0.153 & 0.136 \\
Muscle Strengthening Act & -0.158 & 0.269 & -0.260 & 0.072 & 0.011 & 0.916 \\
FEMALE & & & & & & \\
Cadmium & -0.074 & 0.632 & -0.330 & 0.100 & -0.290 & $0.026^{*}$ \\
Age & -0.095 & 0.514 & -0.161 & 0.416 & -0.184 & 0.144 \\
Weight & 1.602 & 0.470 & 3.431 & 0.242 & 0.842 & 0.534 \\
Standing Height (cm) & -0.461 & 0.520 & -0.428 & 0.463 & -0.607 & 0.252 \\
Body Mass Index & -1.698 & 0.420 & -3.380 & 0.226 & -0.835 & 0.536 \\
Avg. Level of Physical Act & -0.042 & 0.793 & 0.354 & 0.028 & -0.146 & 0.213 \\
Muscle Strengthening Act & -0.081 & 0.598 & 0.003 & 0.987 & 0.976 & 0.333 \\
& & & & & & \\
\hline
\end{tabular}




\section{Discussion and Conclusion}

In this study there was an inverse association between urinary cadmium and estimated VO2 max among white and Mexican American males; for black males the association was positive. However, the association was significant among white males but not significant among Mexican American males. Similarly, an inverse relationship between urinary cadmium and estimated VO2 max was found among female whites, blacks and Mexican Americans. The association was significant among Mexican American females but not significant among white females and black females. The relationship was independent of age, standing height, weight, BMI, muscle strengthening activities and average level of physical activity.

The study may be among the first to use VO2 max as a measure of the effect of cadmium on cardiovascular fitness and associated respiratory health. The results support many findings that chemical pollutants affect respiratory health and therefore cardiovascular fitness. Jakubowski et al (2004) accessed lung function in workers exposed to cadmium and found a significant decrease in maximum expiratory flow at 50\% (MEF 50\%) which suggested exposure resulted in deterioration of lung function causing a mid airway obstruction [34]. Mannino et al (2004) also found higher levels of urinary cadmium were significantly associated with lower forced expiratory volumes in one second (FEV1) in both current and former smokers with similar results on forced vital capacity (FVC). The study further concluded cadmium may be important in development of tobacco related lung diseases [35]. A cross-sectional study of pulmonary function among cadmium alloy 
workers revealed chronic pulmonary obstructive changes resulted from cadmium exposure among Japanese workers who did not have a prior history of acute or sub acute cadmium pneumonitis [36]. By extension, results from the present study suggested an inverse association between urinary cadmium and VO2max.

In addition, racial differences between urinary cadmium and estimated VO2 max were also observed in the present study. The scatter plot of urinary cadmium plotted against estimated VO2 max Figures 2-3 showed white males tended to have a negative slope compared to Mexican American males. This racial disparity is not fully understood from this study. However, the result may be due to age and weight characteristics of the population. White males had highest mean values for age (mean=23) and weight (mean=76) compared to other racial groups. The positive association observed for black males might have been due to the average age of black male participants, which was 18 compared to their white and Mexican American counterparts, which were 25 and 24 respectively. The differences may also have been due to genetics and the different abilities of the subjects in processing lactic acid during aerobic conditioning. The finding is consistent with one study by Andrew et al (1990), who found racial differences among blacks and whites with respect to lactic acid in a marathon race [37]. According to the study, black runners had lower blood lactate levels compared to their white counterparts. The result was that blacks tended to exhibit superior performance and had the ability to run at a higher percentage of $\mathrm{VO} 2$ max than their white counterparts [37]. 
Similar racial differences were also observed for females. There was an inverse relationship between urinary cadmium and estimated $\mathrm{VO} 2$ max with respect to white, black and Mexican American females. Mexican American females tended to be affected relatively more compared to the other racial ethnic groups, as indicated in Figure 2. The differences may have been due to the mean estimated VO2 max, which was highest for Mexican American females (mean $=40)$ compared to the white females $($ mean=36) and black females (mean=37). The difference may also have been due to the mean weight of Mexican American women (mean=70), compared to white females (mean=75) and black females (mean=72). Age may have also played a role in the observed difference. Mexican American females had the lowest average age compared to white females and black females. The observed racial difference may have also been due to genetics and lactate intolerance not assessed in the present study.

The biological basis of the effect of urinary cadmium on VO2 max and the mechanism of cadmium pulmonary toxicity is not fully understood. However, in a study aimed at understanding the effect of cadmium exposure on human fetal lungs fibroblast, ChengFeng Yang (1997), found cadmium caused oxidative cellular damage in the fetal lung leading to pulmonary damage and impairment of gaseous diffusion across alveolar membrane [38]. The effect limited oxygen uptake and cell utilization. Long term continuous exposure to cadmium impacts lung function and cardiovascular fitness negatively. Other investigators obtained similar results. Miller, et al (1974), found intermediate duration exposure to cadmium caused fibrosis in lungs of rats exposed to $2.4 \mathrm{mg} \mathrm{Cd} / \mathrm{kg} /$ day of cadmium chloride after 6 and 16 weeks. Petering, et al (1979), 
observed a reduced static compliance and lung lesions in male rat exposed to $1.2 \mathrm{mg}$ of $\mathrm{Cd} / \mathrm{kg} /$ day for 200 days. Given the results from these studies, it is conceivable similar pathways may also be responsible in the observed relationship between urinary cadmium and estimated VO2 max.

The study has several limitations. First the study was based on NHANES data, crosssectional study, therefore, cause and effect cannot be conclusively established between levels of cadmium and estimated VO2 max. Low cardiovascular fitness status as measured by VO2 max may have preceded urinary cadmium exposure. Second, the study was limited by the selected variables in the regression model. The association between urinary cadmium and estimated VO2 max may also have been due to extraneous factors not related to cadmium. Third the affect of genetics on estimated VO2 max was not controlled. Genetics plays a significant role in stratifying VO2max and lactic acid tolerance levels along racial/ethnic lines. Lower estimated VO2 max may have been due to low lactic acid tolerance. An athlete that takes a longer time to reach the lactate acid threshold will be a better performer compared to the one that takes a shorter time, even though they both may have the same VO2 max. Fourth, the VO2 max used in the present analysis was an estimated measure, and as such, the accuracy of the value obtained may not be a reliable estimate, unlike a direct measure that is considered less subject to information bias. Fifth, current infections or diseases not known to the participants may not have been controlled, which can alter the estimated VO2 max. Finally, the sample size used in the analysis may not have been a representative of the entire population. 
The present study provides several health implications. VO2 max is an important predictor of cardiovascular fitness. Cardiovascular fitness status is used to predict ability to engage in physical exercise, work performance, activities of daily living, outcomes of respiratory conditions such as chronic obstructive pulmonary disease (COPD); chronic bronchitis, bronchiectasis, asthma, emphysema and recovery from cardiac related conditions such as stroke. O’Donovan et al (2005), reported VO2 max was a good predictor of coronary heart disease [39]. Lamonte et al,(2000) also reported cardiorespiratory fitness was significantly associated with coronary heart disease [40]. They further suggested people with low cardiorespiratory fitness are at an increased risk of congestive heart failure. Physical activity and work performance are also predictable by VO2max. A person's work rate is limited by the ability of the lungs and heart to supply oxygen to the muscles at a sufficiently fast rate to meet the energy requirement of the cells. Work rate and exercise outcomes are thus predicted by VO2max.

Further implications of this study are people exposed to high levels of cadmium from various sources tended to have lower VO2max putting them at an increased risk of developing coronary heart disease, having reductions in job performance and activities of daily living, enjoying less physical exercise and limiting pulmonary rehabilitation of respiratory comorbid patients. This study provided new evidence on how increased levels of cadmium in air may be predictive of cardiovascular fitness, which in turn is predictive of certain physical and physiological functions in humans.

In conclusion, our study suggested increased levels of cadmium were inversely related to estimated VO2 max; Since VO2 max is a direct measure of cardiovascular fitness, by 
extension, urinary cadmium was also inversely related to cardiovascular fitness. Also, racial differences were observed between urinary cadmium and estimated VO2 max. White males were more negatively impacted compared to blacks and Mexican American males. On the other hand, Mexican American and black females were more negatively impacted compared to white females. Future research should be conducted to investigate and better understand the racial differences of the effect of cadmium on VO2 max. 


\section{References:}

1. Raizenne M et al. (1996). Health effects of aerosol on North American children: pulmonary function. Environmental Health Perspectives. (6) 23-24

2. Gauderman W J et al (2002). Association between air pollution and lung function growth in Southern California children: result from a second cohort. American Journal of Respiratory and Critical Care Medicine.166. 76-84

3. Sherwin R P. (1991). Air pollution the pathobiologic issues. Journal of Clinical Toxicology. 29: 385-400

4. Oberdoster G. (2001). Pulmonary effect of inhaled ultra fine particle. International Archives of Occupational and Environmental Health. 74: 1-8

5. Agency for Toxic Substance and Disease Registry. Division of Toxicology information branch. Center for Disease and Control.

6. Cortona G, Apostoli P, Toffoletto F, Baldasseroni A, Ghezzi I, Goggi E,Fornari S, Alessio L. Occupational exposure to cadmium and lung function.IARC Sci Publ. 1992;(118):205-10

7. Chan OY, Poh SC, Lee HS, Tan KT, Kwok SF. Respiratory function in cadmium battery workers a follow-up study. Ann Acad Med Singapore. 1988 Apr;17(2):283-7

8. Miller ML Murthy L, Sorenson (1974). Fine structure of connective tissue after ingestion of cadmium:Observation on interstitium on male rat lung. Arch Pathol 98:386-392

9. IARC. 1993.Cadmium and certain cadmium compounds. In : IARC monographs on the evaluation of the carcinogenic risk of chemicals to humans. Berryllium, cadmium, mercury and exposures in the glass manufacturing industry.IARC monographs VOl 58. Lyon France: World Health Organisation.International Agency for Research on Cancer 119-146, 210-236

10. Andersen O, Neilsen J B, Jones M M (1988). Oral cadmiunchloride intoxication mice: effects of dose on tissue damage, intestinal absorption and relative organ distribution. Toxicology 48:225-236

11. Bustueva K A et al (1994). Cadmium in the environment of three Russian cities and in human hair and urine. Archives of Environmental Health 49(4); 284-288 
12. Davidson AG, Fayers P M, Taylor A J, et al. (March 26,1988) Cadmium fume inhalation and emphysema. Lancet 663-667

13. Bernard S M, Samet J M, Grambsch A, Ebi KL, Romieu I.(May 2001). The potential impacts of climate variability and change on air pollution-related health effects in the United States. Environmental Health Perspective. 109 Supp1 2:199-209. Review

14. Edling C, Elinder CG, Randma E. (Oct 1986). Lung function in workers using cadmium containing solders.British Journal of Industrial Medicine.. 43(10):657-62

15. Elinder C G, Edling C, Lindberg E et al (1985) Assesment of renal function in wokers previously exposed to cadmium. British Journal of Industrial Medicine 42:754-760

16. Iwata K et al (1993). Renal tubular function after reduction of environmrntal cadmium exposure: A ten-year follow-up. Archives of Environmental Health 48(3): 157-163

17. Butchet J P et al (1990). Renal effects of Cadmium body burden of the general population. Lancet 336: 699-702

18. Siodin B, Svedenhag J.(1992). Oxygen uptake during running as related to body mass in circumpub boys longitudinal study. European Journal of Appiedl Physiology. 65(2): 150-7

19. Wilmore J H and Costill D L. (2005) Physiology of Sport and Exercise: $3^{\text {rd }}$ Edition. Champaign Human kinetics.

20. Satlin B et al (April 1980). Functional adaptations to physical activity and inactivity. Federation Proceding . 39(5):1506-13

21. Gollnick P D et al. (September 1972). Enzyme activity and fiber composition in skeletal muscle of untrained men. Journal of Applied Physiology. 33(3):31

22. Astrand P O and Rodahl K. (1986) The textbook of work Physiology: Physiological bases Exercise ( ${ }^{\text {rd }}$ ed). New York MCGraw-Hill 
23. Wilkens, Krider, Sheldon (2000). Clinical assessment in respiratory care.Mosby $4^{\mathrm{Th}}$ edition.Pg143

24. Bouchard C, et al (1992). Genetics of aerobic and anaerobic performances. Exercise and Sport Science Reviews . 20:27-58

25. Gonzalez-Alonso and Calet Lose A.l (Jan 2003). Reductions in systematic skeletal muscle blood flow and Oxygen delivery limit maximal aerobic capacity in humans. Circulation. 107; 824-830

26. Susie W J et al (Feb 2006). The influence of age, gender and training on exercise efficiency .Journal of American College of Cardiology. 47; 10491057

27. Hollenberg Milton et al (2006) . Longitudinal changes in aerobic capacity: Implications for concepts of aging. Journal of Gerantology Medical Sciences. 61A 8;851-858

28. Weiss E P et al. (February 2006). Gender differences in the decline aerobic capacity and its physiological determinants during the later decades of life. Journal of Applied Phyiology. 101: 938-944

29. Bunyard L B et al.(1998) Energy requirements of middle-aged men are modifiable by physical activity.American Journal of Clinical Nutrition; 68: $1136-42$

30. Yu I T et al. (September 2004). Impact of air pollution on cardiopulmonary fitness in schoolchildren. Journal of Occupational Environmental Medicine 46(9): 946-52

31. Pollock M L (1973). Quantification of endurance training programs. Exercise and Sport Science Reviews. 1, 155-188

32. Sarsan A. et al (October 2005). The effects of aerobic and resistance exercise in obese women.Clinical Rehabilitation.20: 773-782

33. National Health Nutrition and Examination Survey. Center for Disease and Control CDC. www.cdc.org 
34. Jakubowski M, Abramowska-Guzik A, Szymczak W, Trzcinka-Ochocka M.(2004). Influence of long-term occupational exposure to cadmium on lung function tests results. Int J Occup Med Environ Health. 17(3):361-8

35. Mannino DM, Holguin F, Greves HM, Savage-Brown A, Stock AL, Jones RL.(March 2004). Urinary cadmium levels predict lower lung function in current and former smokers: Data from the Third National Health and Nutrition Examination Survey. Thorax. 59(3):194-8.

36. Sakurai H, Omae K, Toyama T, Higashi T, Nakadate T. (1982).Crosssectional study of pulmonary function in cadmium alloy workers. Scand $J$ Work Environ Health. 8(1):122-30

37. Andrew N B et al.(September 1990). Physiological differences between black and white runners during a treadmill marathon. European Journal of Applied Physiology. 61: (1) 68-72

38. Cheng-Feng Yang et al (July 1997). Cadmium-Induced oxidative cellular damage in human fetal lung fibroblasts. Environmental Health Perspectives.105:7: 712-716

39. O'donovan G et al (January 2005). Changes in cardiorespiratory fitness and coronary heart disease risk factors following $24 \mathrm{wk}$ of moderate or high intensity exercise of equal energy cost. Journal of Applied Physiology. 98: 1619-1625.

40. Michael Lamonte, Patricia A Eisenman, Ted D Adams et al (Oct, 2000). Cardiorespiratory fitness and coronary heart disease risk factors: The LDS Hospital Fitness Institute Cohort. Circulation 102: 1623-1628 


\section{APPENDIX A. CALCULATION OF ESTIMATED VO2 MAX}

The relationship between heart rate and amounts of oxygen consumed is represented by a linear equation of the form $\mathrm{y}=\mathrm{mx}+\mathrm{C}$.

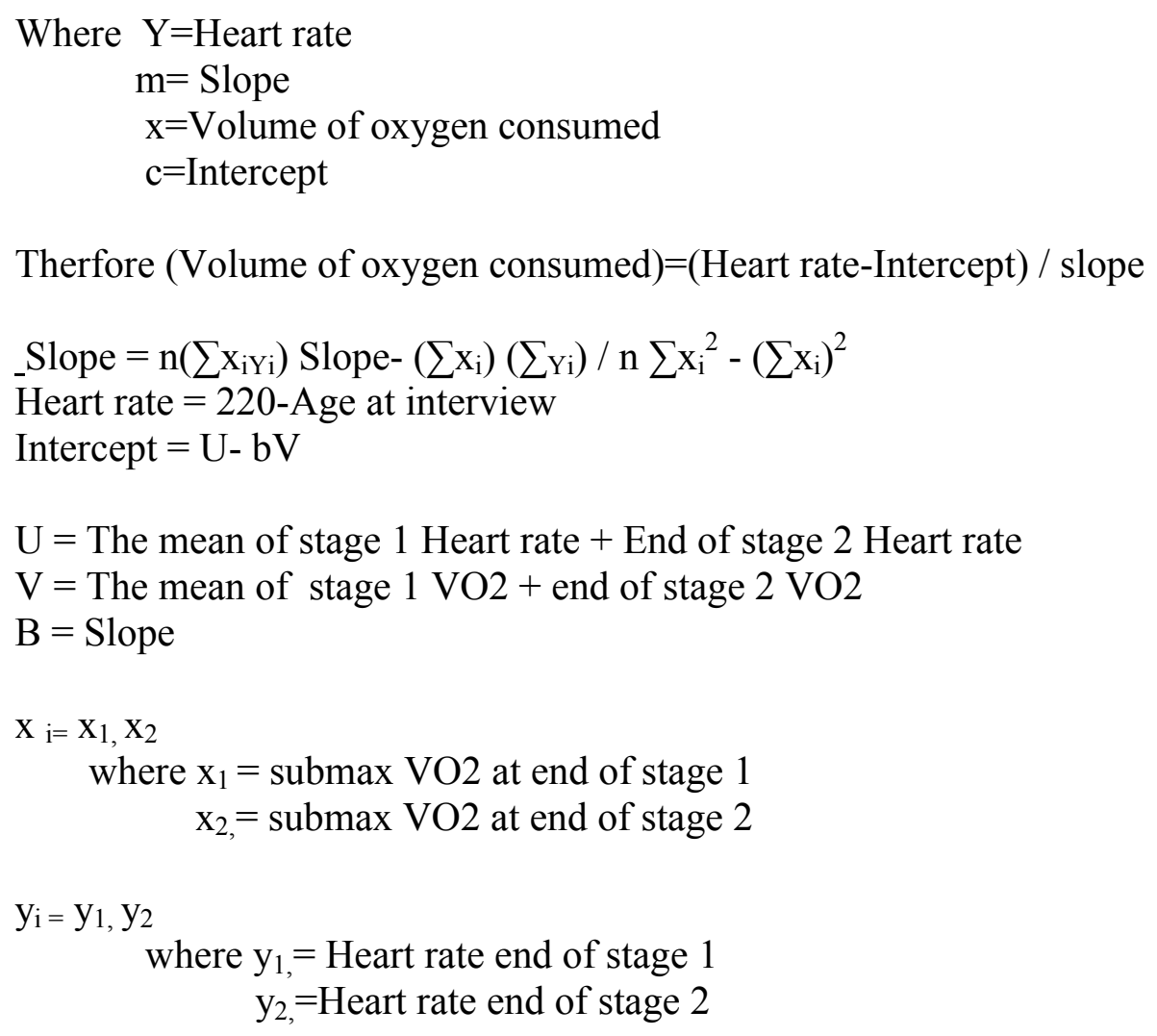




\section{APPENDIX B. CALCULATION OF PREDICTED V02 MAX}

Predicted VO2 $\max =56.365+[1.92] *(\mathrm{PAR}$ CODE $)]-\left[0.381^{*}\right.$ Age at interview $-[0.754 *(\mathrm{BMI})+[10.987 \mathrm{X}(\mathrm{F}=0, \mathrm{M}=1]$ 